\title{
Fisheries Co-management: Organization, Process, and Decision Support
}

\author{
Daniel E. Lane \\ Faculty of Administration, University of Ottawa \\ 136 Jean-Jacques Lussier, Ottawa, Ontario, Canada K1N 6N5 \\ Robert L. Stephenson \\ Department of Fisheries and Oceans, Biological Station \\ St. Andrews, New Brunswick, Canada E0G 2X0
}

\begin{abstract}
Fisheries management requires making complex decisions that account for multiple objectives involving many participants in an inherently variable environment. The form and function of management remains a major strategic issue as we approach the next century. Management approaches for the future need to focus on integrating biological, economic, social and political considerations of fisheries systems through new participatory management structures and processes. This requires institutionalizing a new organizational framework operating under an appropriate process for interdisciplinary decision making. There is a need to overcome disciplinary organizational structures which characterize most established management systems throughout the world, to include relevant participants in effective co-management regimes, and to employ suitable methods of problem solving borrowed from the field of management science. The term "Fisheries Management Science" has been coined to describe the application of the scientific method of problem solving in this more comprehensive fishery management context. It provides an ideal framework for participatory decision making. Implementation requires defining the roles and responsibilities of the participants, the context and methodologies for setting multiple objectives and constraints, the modelling and analysis of alternative management scenarios, and the assessment and management of risk. As an illustration, the specific tools being developed for supporting the in-season co-management initiatives in Atlantic Canada's Bay of Fundy (NAFO Div. 4WX) herring fishery is prescribed.
\end{abstract}

Keywords: co-management, decision analysis, decision support systems, fisheries management, $4 \mathrm{WX}$ herring fishery

\section{Introduction}

The stated objective of the NAFO 1997 Symposium is to "examine the shifts in traditional capture fisheries and new livelihoods for coastal communities" through the undertaking of a "visioning exercise of sustainable fisheries cooperation and management." This issue, regarding the appropriate form and function of fisheries management remains the major strategic issue in fisheries as we approach the next century. Evidence that we are still searching to find better approaches to deal with the complexity of managing fisheries is indisputable. The "Summit of the Sea" meetings held in September 1997 in St. John's, Newfoundland, adopted the goal of sustainable development in the world's oceans and called for the identification of principles and practices to advance that goal. A recent book by Berrill (1997), "The Plundered Seas", demonstrates the international scale of the problem in fisheries management, and the urgent need for change. Later this month, the International Council for Exploration of the Sea (ICES) will establish a committee on Resource Management to promote research into the form and function of management, including evaluation of "the effects of alternative exploitation and management strategies on the resources, as well as of economic and social aspects of exploitation and management" (ICES, MS 1996).

Stephenson and Lane (1995) presented a critique of the current state of fisheries science and fisheries management, and proposed a direction for major change. Foremost among the problems diagnosed was 
the need for more integrated approaches to fisheries management decision making. It was argued that strict disciplinary approaches in the domains of fisheries science or biology, operations management and socio-economic considerations have led to separate management processes for these functions and there was a lack of an appropriate holistic context for the management of commercial fisheries. A framework was prescribed for developing strategic management alternatives and for evaluating these relative to scientific, economic, sociological and political considerations using the structured techniques of decision analysis from the field of management science. "Fisheries Management Science" (FMS) was coined to denote the interdisciplinary roles of fisheries management, fisheries science, and management science in dealing with fisheries problems. In making this proposal, the need for meaningful involvement of interested parties in management - or more appropriately, the need for fisheries co-management was recognized.

As our contribution to the visioning exercise of this symposium, we elaborate on the essence of meaningful co-management. To do this, we examine the issues of the organization, decision making process, and decision support mechanisms of co-management structures in future capture fisheries.

\section{Organization}

The elements of the fisheries systems include the fishing industry (harvestors and processors), government central agency representatives (biologists, economists, fisheries management officials, fisheries officiers), community stakeholders and interested parties (environmental agencies and non-governmental interest groups), as well as the fishery resources and the ecosystem in which they live. The diverse constituencies of these groups must contribute to, and be represented in, policy setting at the strategic (longer term) as well as at the operational (intraseasonal) level. To deal with the complexities of fisheries problems, the management organization must be flexible and balanced to consider the wide range of policy impacts on its participants including the biological impacts on the resource and the ecosystem in which target species cohabitate, the economic impacts on the industry, the community social impacts, and the administrative requirements and limitations. In order to act for the betterment of the fishery system, and to carry out its management functions, the organization must be empowered to make decisions on behalf of its constituents (Jentoft, 1989). Sen and Nielsen (1997) present a spectrum of the degree to which participants are empowered in alternative organizational systems.

The form of organizational representation of the participants in any specific fishery system depends on the particular context of that fishery, and the level of activity of its various groups. There are two principle views of the fisheries co-management organization that have been described:

1. Social inclusion - this view of the co-management organization emphasizes the role of local stakeholders, including native peoples, local communities, and environmental lobbies (NGOs) in the development and critic of fisheries management policy. This social contribution is generally seen as having been excluded from participating in management because of the dominant influences of large corporate interests and government regulatory institutions (Berkes, 1986; Pinkerton and Weinstein, 1995; Pinkerton, 1992, 1993).

2. Industrial organization - this view of the co-management organization seeks to balance management responsibilities for the fishery between government agencies and the commercial fishing industry by working together to meet mutual goals for resource sustainability and for economic viability. This view requires that resource management decision making should be shared with the exploiters of the resource in order for them to become responsible participants in a sustainable fishery (Jentoft, 1989; Jentoft and Kristoffersen, 1989).

While the social inclusion view of co-management has attracted much of the public and academic attention, it is the industrial organization viewpoint that is the focus of our attention as being more relevant to the future of most modern capture fisheries. However, while there are a few reported case studies 
and documented examples, there is little general discussion on which to build a framework for the industrial organization approach to co-management. One reason for this is because each application of a successful co-management organization must be defined uniquely in the context of the fishery, and in terms of the leadership of its participants which is different for every case.

Implementation of co-management organizations that are more than simply consultative (as opposed to truly participative) requires considerable within-industry organization. When this leadership is lacking, as when the factions of the fishery are many (i.e. many, varied participants), it becomes difficult to construct participatory management organizations especially at high levels of inclusion. In these cases, it would become necessary to decompose the organization into manageable subgroups. These subgroups could be defined along local geographical lines, species and stock segregated biological areas, or along fishing gear memberships in order to provide relatively autonomous subgroups. Existing organizational structures tend to experience resistance to change, and often the history of fisheries management has inhibited participation and leadership growth especially among its industrial participants. In those cases where the appropriate leadership has emerged, there have often been a limited number of strong participants in a directed fishery, spatial isolation engendering local ownership of the fishing grounds, and a long-term perspective reflected in short-term interventions and regulations in the fishery.

Organizations dedicated to the fisheries management process are defined by the formalized arrangements by which multiple parties share management functions and responsibilities. Within these arrangements there is a spectrum of stakeholder involvement, e.g. from agency-dominated consultative organizations to formally empowered and participatory decision making bodies. We examine the manifestation of co-management through a generic form of industrial organization and shared management roles of government and industry.

Historically, fisheries management has been driven by biological causes responding to the need to understand the human impacts of stock exploitation for economic gain. Today, we are painfully aware of the underestimation of stock exploitation and the fragility of fish stocks (Munro and Gordon, 1996). The post World War II response of government-led fisheries science agencies in response to the need for more precise information on renewed exploitation, was to expand their scientific research infrastructure. The result, evident in many developed nations, is the existence of centrally controlled, publicly funded fisheries agencies with major emphasis on the scientific research function. Fisheries management is often dependent on the "scientific advice" above all other considerations in the decision making exercise.

Other components of the typical organization include the fisheries operations tasks (industry liaison, and enforcement and monitoring), and a strategic policy and economic planning groups. This group is staffed by mobicentric civil servants who tend to move horizontally among government departments without necessarily acquiring career ties to the fisheries agencies (Luthans, 1977). Science staff, on the other hand, with their highly specialized training in biological techniques and research, are less likely to migrate. The affect is to maintain stability, corporate memory, and growth in this branch but not necessarily in other branches of the fisheries organization. Although movement across functions within the fisheries organization is encouraged and may even occur, it is minimized by the required, narrow knowledge base that define each functional group. Consequently, there can be little integration of tasks and minimal awareness of responsibility across separate functions.

By way of illustration, Fig. 1 presents a summary of the Department of Fisheries and Oceans (DFO) of Canada organizational chart. This is an example of an organization characterized by the functional arrangement of the fisheries institution built on disciplinary lines. 


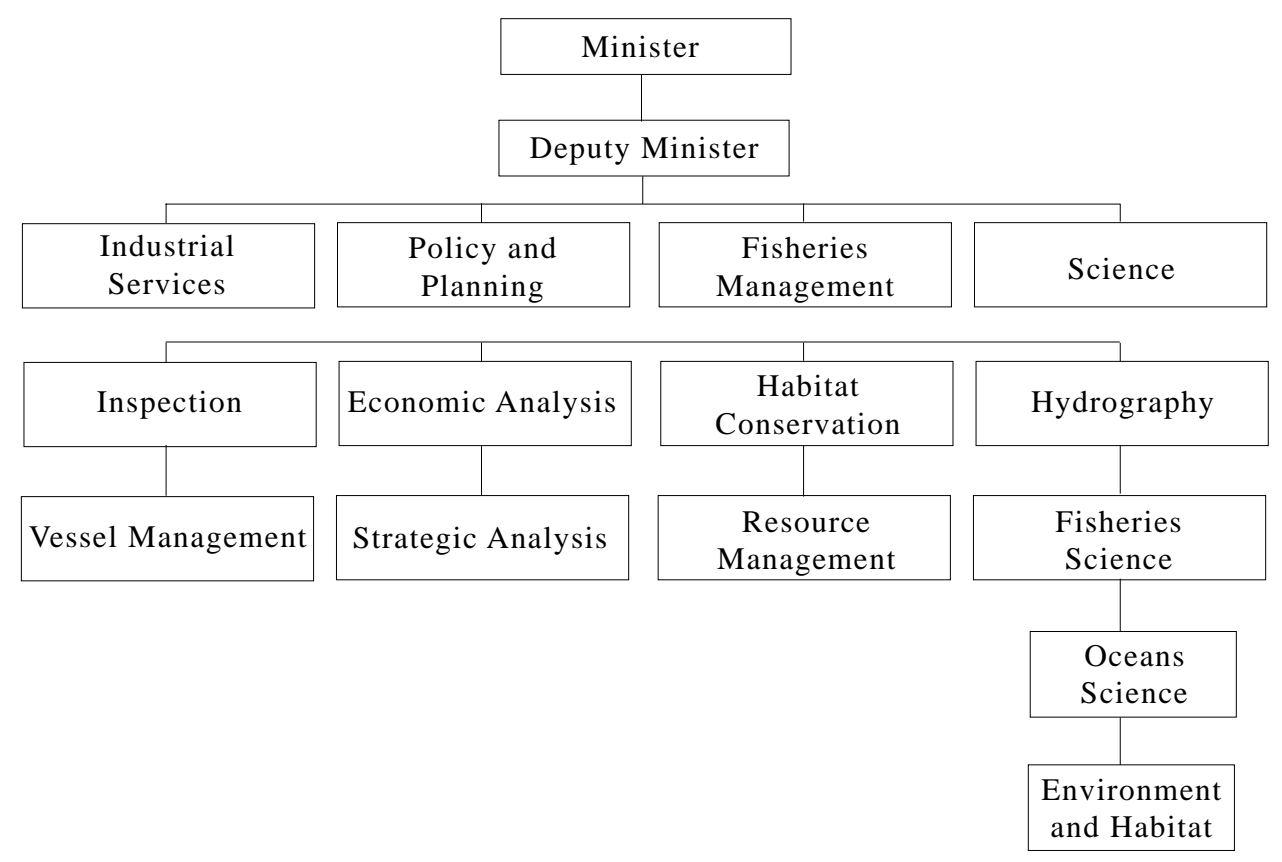

Fig. 1. DFO Canada Organization Structure defined along functional, disciplinary lines.

The historical primacy, relative domination, and ongoing stability of the science branch in this typical arrangement compared to the other functional areas of the organization, has resulted in a dependence on the science activity and a separation of science from the other areas. Similarly, the historical importance of the scientific advice has meant that other branches of the organization have evolved as reactive and subordinate to that primary advice. The result is an organization that is split along functional lines in its actions and responsibilities.

In times of fiscal crises, e.g. a tightening of the public purse and restricted funding to government departments, and the collapse in fish resources, the natural response of the functional fisheries organization is to "close ranks" in support of its rank and file functional membership. This response can result in further cross-functional conflict, institutional ill will, and declining morale. Ironically, as evidenced in the events played out recently in the Canadian media regarding science and politics (Hutchings et al., 1997 a and b; Doubleday et al., 1997; Healy, 1997), the consequences of closing ranks around functional membership can result in defections and demands for even greater independence of the functional group from "bureaucratic" decision making. In the case in question, there have been suggestions for removing the fisheries science branch completely from its bureaucratic environment to create a completely separate and independent (from public policy decision making) body that would act uniquely on the issue of stock conservation (Hutchings et al., 1997a). Typical responses of this type have been termed "The Republic of Science" by its dissenters. The empirical evidence prior to and since the recommendations of the Lamontagne Commission on science policy in Canada (Lamontagne, 1973) clearly indicates that the Canadian public is not well served by such a costly, non-coordinated arrangement (de la Mothe and Paquet, 1994). It is difficult to imagine that the current public appetite for a freely funded "Republic of Fisheries Science" would be acceptable.

Our organizational vision for the fisheries institution of the twenty-first century is diametrically opposite to the "Republic of Science" option and the continuation of the fisheries management organization built along functional lines. Instead, to account for the interdisciplinary complexity of fisheries management, we envisage organizations that can respond in an integrated fashion to the demand for interdisciplinary expertise. Such an organization will be constructed around the activities and output of fisheries management itself. In as much as the fisheries operate on a regular, seasonal basis, management activities and 
interventions express themselves at the scale of in-season operations. The organization will therefore be constructed from the bottom-up, beginning with this lowest level of required decision making at the inseason level. Since the issues that arise at the lowest level involve the biology of fish stocks, the economics of the harvesting and processing sectors, the social structure and administrative activities (e.g. licensing, monitoring, etc.), the organization must be comprised of experts capable of responding to these information needs. Figure 2 presents an example organization constructed around the management of individual fisheries and supported by dedicated, interdisciplinary management teams. In this structure, the functions of science, operations management, and policy are carried out within the particular context of a given fishery and for all fisheries separately.

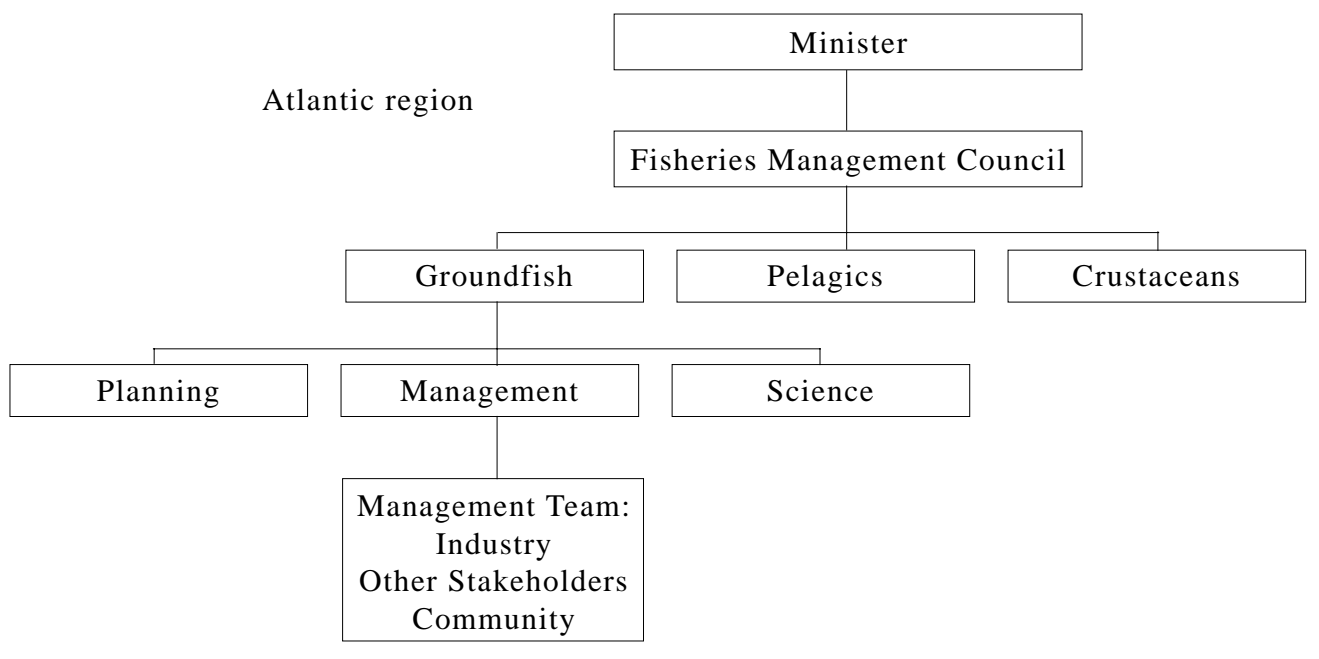

Fig. 2. Fisheries management activity-based organizational structure.

The shift from functional to fishery management team organizations responds to the recognized need for more integration in fisheries management. This shift has begun to occur within existing functional organizations. For example, the Canadian case study of the Scotia-Fundy herring fishery is a case in point. Elsewhere, international institutions such as the OECD (OECD, 1997) and ICES (ICES, 1997) are raising questions about how to integrate all aspects of fisheries information into effective decision making for national and international fisheries issues.

The purpose of the organizational structure is to provide support for its decision-making processes. In the following section we analyze the decision-making processes inherent to the integrated fisheries comanagement organization. In doing so, we define the roles of the management team.

\section{The Co-management Decision Making Process}

The fisheries management process describes the manner by which the legitimate organization makes decisions in the fishery. There are two important issues here. First, a legitimate organization is one that is empowered to make the appropriate decisions. Typically, governments are mandated by law (as in the Fisheries Act of Canada) to (i) conserve fish resources, and (ii) ensure economic viability. However, as we have suggested previously, government fisheries agencies have been largely unsuccessful in carrying out this broad mandate. Alternatively, in the co-management organization, management teams must be empowered (by the necessary legislation) to make operational decisions in the fishery. Formal empowerment of other than strictly government agencies has been a major stumbling block to integrated decision making. Australia, for example, has enacted appropriate legislation providing the Fisheries Management Authority (AFMA) through it fishery Management Advisory Committees (MACs, interdisciplinary teams 
of industry, agency, NGO, and community interests) with the mandate to take decisions for which each MAC is responsible. The Australian model provides a most useful example of participatory decision making in fisheries (McColl and Stevens, 1997).

Secondly, in making decisions to resolve fisheries management problems, the process should follow logical steps in a structured decision making approach. In this regard, fisheries can look to the field of management science for methodologies and approaches to structured decision making. Briefly, the process should treat complex problems in a structured way by detailing: (i) the problem definition, specific objectives and constraining factors, (ii) the generation of alternatives for problem resolution, (iii) the evaluation of the potential effectiveness of alternative decisions in relation to the stated mission of the organization, and (iv) tracking and feedback response to the actual versus anticipated impacts of the implemented decisions (Lane and Stephenson, 1995).

Figure 3 illustrates the dynamics of the co-management decision making process. This process features the activities of the management team in developing and evaluating decision alternatives and in tracking the anticipated versus actual results of past decisions taken.

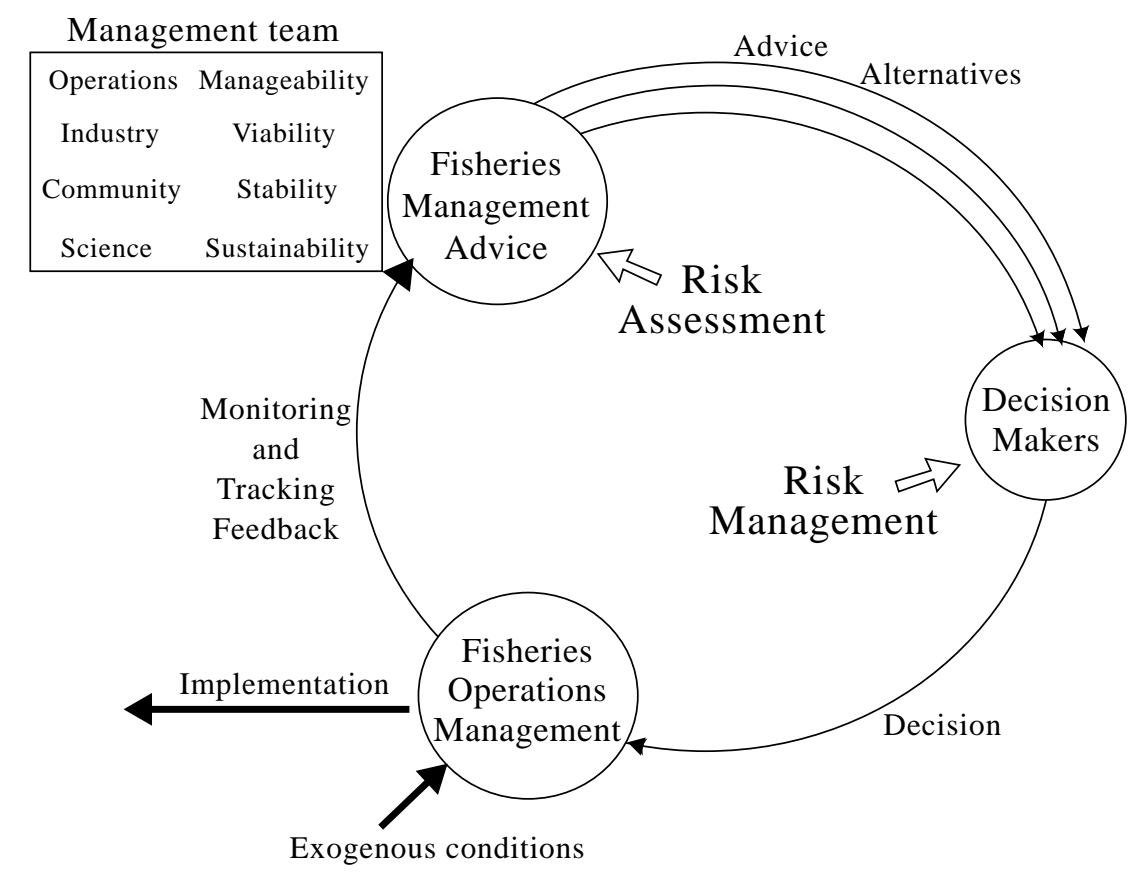

Fig. 3. Management team decision-making process (adapted from Lane and Stephenson, MS 1995).

Provided below are the basic principles of the management decision making process envisaged as providing direction and support to achieving responsible and sustainable fisheries management into the 21 st century.

1. Manage by objectives and continuous improvement - the dynamic process of management involves the ongoing movement toward corporate and institutional targets. By keeping these absolute targets in mind, the organization focuses its energies - both short term and strategic - on specific realizations of its mission. 
2. Industry partnership with government and leadership role - the paternal approach to fisheries management has not been successful because it is done at the exclusion of active participants, e.g. the fishing industry. In order to allow these participants the opportunity to express their conservation ethic, it is necessary to give them the responsibility to carry it out as partners in the decision making process. Similarly, the industrial partners must have the continued trust of the constituents they represent and the leadership capable of communicating the management team consensus positions to each of its members.

3. Government in decision support role - the shift in power and responsibility away from the government as solely responsible for conservation of the resource, transforms the role of government agencies to one of decision support for the decision making process overall. As such, the institutional experts are important and indispensable contributors to the decision process in support of consensus decisions of the management team rather than the ultimate politically motivated decision makers.

4. Cost recovery - the empowerment and responsibility of the industry includes the recognition that the functions of government agencies at the disposal of industry provide a value-added function. The value of this decision support and administrative functions for licensing, data collection, stock assessment, monitoring and enforcement are all activities from which the industry benefits. Accordingly, some portion of the costs of these activities must be recoverable.

5. Rights-based characteristics - the process of participatory decision making explicitly assigns rights and privileges to all responsible participants. In our view, these rights will mark the start of an evolution toward more permanent and restricted access in fisheries and a denounciation of the common property ethic. The recognition of the failure of "open access" or "competitive" fisheries management regimes is now pervasive. In their place, the success of quota systems (individual transferable quotas or ITQs, nontransferable IQs, community quota systems, effort quotas) seem to indicate a strong shift in management regimes. The input of the management team will be mandatory in initiating the specifics of the rights-based system appropriate to each individual fishery. However, the evidence to date suggests quota systems are very flexible and come in many forms adaptable to fisheries.

Fisheries management problems generally have multiple and conflicting objectives: (1) economic objectives - the performance of commercial fishery sectors toward achieving a minimum desirable level of return; (2) social objectives - the public benefits derived from ownership and consumption of the resource including maintaining target levels of seasonal employment in fish harvesting and processing; and (3) biological constraints - stock attributes (e.g. a desirable age composition) over and above the establishment of minimum, sustainable stock target abundance levels that are the primary constraints of the fisheries management problem. All objectives of fisheries problems are measurable valuations that can be used to compare the expected performance of alternative policy options. Expectations of these measures provide the means of ranking the potential effectiveness of alternative strategies for decision making. The analysis implied by including these measurement schemes requires the tools to complete these tasks. The decision tools needed to support management team decision making within the co-management organization are discussed below.

\section{Decision Support Tools}

The management process requires tools to assist in the development and evaluation of decision alternatives. The most useful tools take the form of appropriately conceived quantitative models of the fishery system used for anticipating, projecting, and estimating multiple performance criteria in support of the decision making process. Analytical models should take into account the links among biological, economic, social and administrative considerations as well as system uncertainty and errors in observation. 
Evaluating decision alternatives with knowledge of the range of output possibilities provides the first part of risk analysis, risk assessment. Risk assessment, takes all implications of decisions into account and is the task of the management team toward the development and evaluation of decision alternatives. Consideration of the trade-offs of the multiple criteria allows the decision alternatives to be ranked accordingly. This is the second part of risk analysis, or risk management (Lane and Stephenson, 1998). It is also the responsibility of the management team to consider these trade-offs explicitly and to rank the decision options. In the case where a single decision maker has the final decision making authority, the risk management exercise should leave no doubt as to the expected implications of all options as well as the recommended ranking of the options based on defined trade-offs. Finally, monitoring and ongoing accountability of past decisions based on desirable performance over the planning period is important to determine the ongoing effectiveness of the decision-making strategy. Such ongoing monitoring of decision performance, and continuous improvement over time are the ideas behind "total quality management" (Deming, 1982) and "management by objectives" (Drucker, 1954) - approaches with their associated decision support tools that have been applied successfully in many business settings. For example, when actual observations in a control chart of absolute measures vary significantly from expected results, this "signal" should cause an automatic adjustment in operational strategy to take effect. Feedback from systems which are "out of control" are not behaving as expected. This feedback initiates continuous adjustment in an effective decision process.

In support of management decision making, specific tools should be developed. For example, a suite of descriptive and analytical tools for successful fisheries management in the future could include the following:

- Spatial-temporal stock database - a database of in-season spatial and temporal stock observations containing all available information sources especially those collected (on a cost recovery basis) by the fishing industry from vessel logbook entries, and stock survey observations.

- Industry performance database model - periodic pro forma evaluation of the economic performance of the sectors of the fishery. This tool would also provide seasonal projections of socioeconomic performance of the industry. It would also be used to anticipate the economic impacts of alternative decision strategies (Lane and Stephenson, 1996).

- In-season fishery system analysis - estimation of in-season stock abundance dynamics and the linked bioeconomic impacts on the fishery. This analysis is based on a probabilistic model of seasonal stock and fishery dynamics. Repeated in-season observations from the spatial-temporal database would be used to update probabilistic stock size estimates calculated using Bayesian updating and statistical analysis (Lane and Stephenson, MS 1995).

- Risk analysis - comprised of risk assessment and risk management as quantitative analyses of management alternatives. The probabilistic analysis of risk assessment describes the range of anticipated outcomes, measures and their probability of occurrence for alternative management policies. The risk management analysis identifies trade-offs among the multiple objectives of the fishery and the performance measures of alternative policy options resulting in a ranking among alternatives (Lane and Stephenson, 1998).

- Aggregate stock assessment - estimation of stock size. This analytical tool provides a static estimate of the aggregate abundance of the stock. Existing assessment methods include the widespread use of Virtual Population Analysis (VPA, least square parameter estimation) methods where applicable to calculate point estimates of cohort strength and total population size. These traditional analyses should be compared to the independently derived in-season fishery system stock estimates to improve stock estimation reliability (Hilborn and Walters, 1992).

- Feedback analysis - this important tool compares the actual multiobjective impacts of an implemented decision policy with the recorded and anticipated performance of the decision taken. The gap between the actual and expected decision performance is the measure of the ability to manage and control the system. A wide gap requires a review of the uncertainty of decision evaluation and the need to apply a more conservative adjustment to subsequent decision making. 
The suite of tools to support management decision making represent a well-established set of operational business methodologies for decision analysis from the field of operations research. From the vast experience of other business sectors, there is substantial formal and applied evidence of the usefulness of such integrated systems in decision making (Lane, 1992).

By way of example, the following section presents recent experience of the Scotia-Fundy commercial herring fishery in moving towards its own realization of responsible and sustainable fisheries.

\section{The Scotia-Fundy Herring Fishery}

The NAFO Div. 4WX herring fishery is the largest herring fishery in the western Atlantic, with annual landings in the order of 100000 tons. This Canadian commercial fishery involves a variety of gear types including fixed gears (weirs, shutoffs, and gillnets), and a dominant mobile gear sector fleet of approximately 25 purse seine vessels that take over $80 \%$ of the annual catch. The commercial fishery has survived major changes in market emphasis and demand, and has been dominated at different times by sardine, fish meal, fillet and roe markets.

This herring fishery has been at the forefront of innovative fisheries management (Stephenson et al., 1993) and twice in its history (both in response to crises) has had advanced co-management relationships. Management has been carried out via annual management plans developed by DFO in collaboration with the Scotia-Fundy Herring Advisory Committee (SFHAC) with a general continuity on elements such as gear sector suballocation, and ITQ transfers has been imposed by a longer term plan established in 1983 . A major change in stock status prompted development of an in-season management system in 1994. The in-season management system represents a form of fisheries co-management, and it is the subject of this case study.

Stephenson et al. (MS 1995) summarized the recent problems in the fishery. The 1995 stock assessment indicated that the spawning stock had declined from about 600000 tons in the late-1980s to perhaps as low as 200000 tons. Consequently, DFO insisted on a cautious approach in the management of the Div. 4WX stock complex and set a reduced TAC for 1994-95 at 80000 tons (reduced from 150000 tons TACs in previous years). Moreover, this TAC was set only on an interim basis to be reviewed throughout the course of the fishery.

The resulting Div. 4WX herring management plan stressed the importance of monitoring progress and signals in the 1995 summer fishery, particularly related to the spawning grounds, and required an inseason re-evaluation of the fishery. To meet these requirements, the Scotia-Fundy herring purse seine monitoring working group (MWG), a subcommittee of the SFHAC, was established to evaluate information from the fishery on an ongoing basis. The committee was comprised of representatives from industry (the purse seine fleet, and the processing sector), and the federal government (fisheries operations/management, and fisheries scientists).

The importance of timely and effective decisions to be made by the MWG during the 1995 season necessitated new information and structured approaches to dealing with the issues. This information included: (1) joint industry and DFO monitoring of stock size in fishing areas; (2) rapid compilation of data for dissemination to the MWG; and (3) analysis and use of the data in a form appropriate for consensus decision making. The MWG was provided with the mandate and empowered to make decisions on areal fishing limits for the remainder of the summer purse seine fishery. The committee, jointly chaired by a DFO manager and an industry representative, met routinely in person or by conference call to review new information and to decide on a course of action. Considerable progress was made on obtaining appropriate information on which to base decisions. Information collected from the summer fishery included:

Statistics - records of all vessels' searching activity and catch locations available on a daily basis and summarized and plotted weekly. 
Sampling - very thorough coverage of all aspects of the summer fishery for size and biological characteristics resulted from increased presence of biologists on the fishing grounds, observers on fishing vessels, and from sampling done by members of the industry (vessels and plants). Length frequency by fishing ground and week were made available and discussed while the fishery was in progress.

Surveys - a series of stock surveys was undertaken of major spawning areas using commercial vessels. Sonars and sounders were used to document number, location and approximate size of herring schools. In most successful surveys, several vessels worked together to provide rigorous coverage of the target areas.

Since at the time, the primary concern was for the biological state of the stock (especially the state of abundance on the individual spawning grounds), biological observations formed much of the in-season information brought to the MWG for discussion. It was essential to the MWG to develop criteria against which these observations could be compared. To this end, tables of expected biological observations (size and age composition, relative local abundance, location and distribution, fat and feed content) include an expected range of values for each was constructed. This "checklist" (Table 1) was used as the basis for decision making from the biological observations on individual spawning components and discrete fisheries.

TABLE 1. Checklist for biological considerations in Div. 4WX herring fishery decision-making.

\begin{tabular}{|c|c|c|}
\hline Item & Positive & Negative \\
\hline \multicolumn{3}{|l|}{ Spawning areas } \\
\hline $\begin{array}{l}\text { Times } \\
\text { Location } \\
\text { Relative amount }\end{array}$ & $\begin{array}{l}\text { Normal } \\
\text { all traditional areas } \\
>\text { or as expected }\end{array}$ & $\begin{array}{l}\text { late or early } \\
\text { missing in expected location } \\
\text { few }\end{array}$ \\
\hline \multicolumn{3}{|l|}{ Size (age) composition } \\
\hline $\begin{array}{l}\text { Compare with average number- } \\
\text { at-size }\end{array}$ & $\begin{array}{l}\text { High abundance of large }(4+\text { or } \\
>26 \mathrm{~cm}) \text { fish }+ \text { reasonable presence } \\
\text { of smaller fish }\end{array}$ & narrow age span; missing year-classes \\
\hline \multicolumn{3}{|l|}{ Distribution } \\
\hline $\begin{array}{l}\text { Distributed as expected from } \\
\text { in previous years }\end{array}$ & $\begin{array}{l}\text { Presence in all expected areas } \\
\text { (last } 10 \text { years) }\end{array}$ & missing in some expected areas \\
\hline \multicolumn{3}{|l|}{ Relative abundance } \\
\hline $\begin{array}{l}\text { Observations and fishing success } \\
\text { expected areas }\end{array}$ & $\begin{array}{l}\text { lots of fish observed; high } \\
\text { proportion of vessels with success- } \\
\text { ful sets/trips; positive cumulative } \\
\text { catch }\end{array}$ & $\begin{array}{l}\text { lack of sets; unsuccessful nights; few } \\
\text { fish; small catches; }\end{array}$ \\
\hline \multicolumn{3}{|l|}{ Behaviour } \\
\hline $\begin{array}{l}\text { Fish behaviour as related to fishing } \\
\text { success, and in relation to previous } \\
\text { experience }\end{array}$ & $\begin{array}{l}\text { lots of fish }- \text { but too deep/shallow or } \\
\text { avoiding gear }\end{array}$ & $\begin{array}{l}\text { fish acting abnormally; only small, } \\
\text { scattered bunches seen }\end{array}$ \\
\hline \multicolumn{3}{|l|}{ Physiology/condition } \\
\hline $\begin{array}{l}\text { Condition as related to previous } \\
\text { years }\end{array}$ & $\begin{array}{l}\text { feeding and high fat at appropriate } \\
\text { times }\end{array}$ & $\begin{array}{l}\text { abnormal conditions of fat and feed } \\
\text { (as in 1994); high proportion of small } \\
\text { fish }\left(<10^{\prime \prime}\right) \text { mature }\end{array}$ \\
\hline \multicolumn{3}{|l|}{ Environmental info } \\
\hline $\begin{array}{l}\text { Water temp, salinity, plankton } \\
\text { abundance }\end{array}$ & & \\
\hline
\end{tabular}


This analysis took considerable effort on the part of the MWG participants. It involved weekly conference calls and meetings and even more frequent meetings during the active fishing period. It also required increased sampling and more rapid summary and dissemination of information to estimate stock availability prior to fishing.

The results of the in-season management process led to the imposition of further restrictions on its own industry by the MWG in the form of closures of individual spawning grounds in response to negative observations or a high degree of uncertainty in real time. In addition to the biological checklist, the MWG found it natural to include multidisciplinary aspects (prices, markets, and equitable distribution among the fleet, monitoring and enforcement) in the discussions. Recommendations took these aspects into account implicitly. A more detailed account of the 1995 fishery information is available in Stephenson et al. (MS 1996).

The in-season management approach was continued for the 1995-96 fishery. In addition to the objective of monitoring observations of relevance to the overall TAC, the in-season management approach was used to spread fishing effort appropriately among various spawning components of the stock complex. This was accomplished through the emergence of a "survey, assess, then fish" protocol which required surveys and MWG review prior to fishing on spawning grounds, and limited fishing on a portion (less than or equal to $20 \%$ ) of the estimated biomass.

The program of in-season management was extended from the purse seine sector to the gillnet sector in 1996. The approach resulted in routine surveying of spawning grounds by as many as 50 vessels in one night and a number of consensus decisions to limit fishing activity based on observed abundance, fish size, market, or operational considerations.

The results of in-season management has been enhanced consensus on issues, increased care for the resource, and improved compliance with management regulations in this fishery.

The experience of the Scotia-Fundy herring fishery with in-season management in 1995 and 1996 represents a major step toward realizing a form of industrial co-management. The empowered management group, comprised of the main participants in the fishery system and the consensus-based decision process using real-time quantitative measures and tools as decision aids, marks a radical change away from disciplinary, hierarchical and government controlled decision making, toward the inclusion of interdisciplinary aspects of management.

The following analyses consider the in-season management experience of the management group and address its needs in the evolution toward decision making through FMS.

The management group was conceived and continues to exist in an atmosphere of crisis surrounding the perceived declining status of herring stock abundance and the potential for overexploitation by the dominant purse seine fleet, and, more recently, by the reactivated gillnet fleet. As such, the immediate concern and direction of the management group is that of monitoring and reacting appropriately to signals about the biological status of the stock. The short-term urgency of the perceived stock status precludes further discussion on other longer-term issues and considerations. Although decisions taken by the management group were nearly always rationalized on the basis of industry economic viability and the equitable distribution of fishing rights, these issues were only considered implicitly in the decision making process.

The specification of a strategic plan would entrench explicitly what is currently implicit in decision making. Moreover, the formal statement of these considerations in a mission statement would provide guidelines on how to deal with differing problem situations not simply related to urgent biological concerns. As such, the organization would be obligated to record their complete justification of actions as a means of sustaining the management process. A formal industry-government strategic planning exercise 
is being considered. The rigour of this process would help the organization focus on how it will make future decisions and would serve as documentation and guidelines to assist future decision-makers.

1. Organization. The four main groups active in the management of the herring fishery include: (1) the independent fishermen's associations representing the different gear sectors (weirs, gillnets, and seiners) and geographically defined local groups; (2) active shore-based processing firms specializing in herring; (3) the governments of Canada through the DFO and the provincial governments of Nova Scotia and New Brunswick; and (4) the diverse group of community members, fishermen in other fisheries, special interest and lobby groups who are impacted by the activities of the Scotia-Fundy herring fishery. The management group has been comprised of representatives from a portion of the fishing industry (harvesting and processing) as well as government officials. The industry representatives were all individuals who were empowered by their respective associations to act on their behalf. However, initially they represented only the dominant purse seine gear sector of the harvesting sector (and subsequently in 1996, gillnetters) at the exclusion of other fixed gear herring fishermen (e.g. weir operators). There were no specific members to represent the wider community of interested parties/"stakeholders".

The exclusion of the latter group diminished the scope and decision making ability of the management group as was evidenced by the protests of the lobby against the purse seiners' access to some winter 1995 herring aggregations on the southeast shore of Nova Scotia. The problem of effective representation of this diverse stakeholders' group notwithstanding, it would be incumbent on future management organizations to establish more formal information links to its peripheral community. More importantly, the exclusion of fixed gear representatives from herring decision making bodies risks creating further animosity between these different harvesting groups. Inasmuch as the fixed gear groups have parallel associations to the seiners, representatives from these groups could be included in the direct management process to the extent that they will be affected by decision taken in the fishery.

2. Management Process. A key development in the management process has been its "scale" of application. Historically, the management decisions were made based on annual stock assessments as input to biannual meetings with participants for determining the annual management plan and the seasonal aggregate catch limits. In-season interventions were reserved to enforce occasional variance orders and to monitor the aggregate exploitation of the fishery. In contrast, the in-season decision making process tracks vessel activity from fishing area to fishing area. This in-season perspective not only provided the means needed to manage exploitation of the individual spawning grounds, but also required a direct, ongoing communications link among all the participants. Consequently, decision making moved from an annual standardized procedure, to ongoing multiple and directed decision interventions in consultation with participants. The industry's link to the ongoing decision process lies in its acquisition of real-time data and the use of industry observation. When data are required at this level, its reliability and usefulness are clearly enhanced.

Initially, the roles and responsibilities of the participants in the in-season management process were discussed and debated. They have since become more comprehensive, but as yet not fully structured or empowered by legislation to consider the multiple objectives of the fishery. Nevertheless, a better understanding and appreciation has been realized for the contributions of each participant group toward accomplishing the organization's mutual goals. Harvesters and processors have become more responsible for providing timely and accurate information from the observations of their own constituents (including extensive surveys and sampling), for maintaining the confidence of their membership in the process, and for developing and supporting the consensus position of the decision making process. Government researchers have become more committed to providing practical, relevant information directly complementary to in-season decision making (e.g. spawning ground stock abundance estimates). Government administrators have become more responsible for the orderly prosecution and implementation of the decisions by providing logistical 
and communications support to the fishing industry and all participants. Finally, other stakeholders have participated in the consensus building process by sensitizing the decision making body to the ramifications of its decision alternatives.

The management team approach to decision making could be improved by formalized and enhanced in-season roles of the participants. The Team would ultimately be held accountable for decisions made and therefore responsible for tracking the performance of past decisions by comparing measurable actual impacts of decisions taken with the anticipated results. This feedback should then be used to adapt future decisions toward achieving predefined strategic goals.

3. Decision Support. The in-season experience of the fishery led to the development of some tools (in the form of a biological checklist, Table 1, and industry surveys) to assist in the interpretation of observations from the fishery. In support of management decisions for the herring fishery, other specific tools are being developed for structured decision making. The suite of descriptive and analytical tools include the following:

- Spatial-temporal stock database - a database and geographic information system (GIS) for the herring fishery has been prepared based on historical logbook data since 1986. Analysis is continuing on the form and content of descriptive information reporting useful to in-season decision making. An internal analysis of these data has been carried out for the Scots Bay spawning area.

- Industry performance database model - pro forma business statements have been prepared for each sector of the Div. 4WX fishery. This information has also been used to analyse the intraseasonal and interseasonal impacts of market fluctuations for herring products (e.g. roe price changes), changes in herring catches and adjustments in quota allocations to gear sectors (Lane and Stephenson, 1996).

- Simulation analysis - an analysis based on a probabilistic model of in-season herring stock dynamics and the relative strengths of spawning stocks has been carried out using a partial observable Markov chain with Bayesian updating. The results are used to estiabundance and to provide an independent comparison to the aggregated VPA stock abundance estimates (Stephenson et al., MS 1995; MS 1996). These analysis is also used to prepare the risk assessment component of risk analysis.

- Risk management - data from in-season deterministic industry performance analyses and stock abundance distributions from the simulation analysis form the basis of risk management. Alternative trade-off functions among the multiple objectives and performance measures of the fishery are examined to record the ranking among alternative policy options.

These tools represent a well-established set of methodologies for decision analysis from the field of operations research. As such, there is substantial formal and applied evidence of the usefulness of such systems (Lane, 1992). The process of fully integrating these decision support tools into the in-season management process is continuing.

\section{Conclusions}

The Scotia-Fundy herring fishery demonstrates that a more effective fisheries management system can be developed by increasing the representation and decision making responsibility of fishing industry participants, and by shifting the scale of management from the aggregate to the in-season level of operations. It is suggested that this management system can be improved further by (i) entrenching and empowering, through legislation and cost recovery guidelines, the roles and responsibilities of the participants in the management process, and (ii) applying decision support tools for strategic planning and measuring the performance and feedback of management decisions. 


\section{Acknowledgements}

The authors thank Dr. Mike Sinclair for comments made on an earlier draft of this paper. This work was funded in part by operating grant OGP0122822 to D. Lane from the Natural Science and Engineering Research Council of Canada.

\section{References}

BERKES, F. 1986. Local level management and the commons problem. Marine Policy. October. 215-29.

BERRILL. M. 1997. The Plundered Seas. Greystone Books, Vancouver, Canada.

DE LA MOTHE, J. and G. PAQUET. 1994. Circumstantial evidence: a note on science policy in Canada. Science and Public Policy, 21(4), 261-268.

DEMING, W. E. 1982. Quality, Productivity, and Competitive Position. MIT Center for Advanced Engineering Study, Cambridge, Mass.

DOUBLEDAY, W. G., D. B. ATKINSON, and J. BAIRD. 1997. Comment: scientific inquiry and fish stock assessment in the department of Fisheries and Oceans. Can. J. Fish. Aquat. Sci., 54: 1422-1426.

DRUCKER, P. F. 1954. The Practice of Management. Harper \& Row: New York.

HEALY, M. C. 1997. Comment: The interplay of policy, politics, and science. Can. J. Fish. Aquat. Sci., 54: 14271429.

HILBORN, R., and C. J. WALTERS. 1992. Quantitative fisheries stock assessment: choice, dynamics, and uncertainty. Chapman and Hall: New York.

HUTCHINGS, J. A., C. J. WALTERS, and R. L. HAEDRICH. 1997a. Is scientific inquiry incompatible with government information control? Can. J. Fish. Aquat. Sci., 54: 1198-1210.

1997b. Reply: Scientific inquiry and fish stock assessment in the department of Fisheries and Oceans. Can. J. Fish. Aquat. Sci., 54: 1430-1431.

ICES. MS 1996. Report of the Bureau Working Group on Strategic Planning for Scientific Cooperation and Advice. ICES C.M. Doc., No. Gen:7.

JENTOFT, S. 1989. Fisheries co-management: delegating government responsibility to fisheries organizations. Mar. Pol., April, 137-154.

JENTOFT, S., and T. KRISTOFFERSEN. 1989. Fishermen's co-management: the case of the Lofoten Fishery. Human Organization, winter, 48(4): 355-365.

LAmONTAIGNE, M. 1973. A Science Policy for Canada. Report of the Special Committee on Science Policy. Volume 1. A critical review: past and present.

LANE, D. E. 1992. Management science in the control and management of fisheries: an annotated bibliography. Amer. J. Math. Man. Sci., 12(2,3): 101-152.

LANE, D. E. and R. L. STEPHENSON. 1995. Fisheries management science: the framework to link biological, economic, and social objectives in fisheries management. Aquat. Liv. Resour., 8: 215-221.

MS 1995. A decision making framework for the development of management plans. DFO Atl. Fish. Res. Doc., No. 80.

1996. SATURN: A framework for integrated analysis in fisheries management. Special Issue of INFOR, 34(4): $156-180$.

1998. A framework for risk analysis in fisheries decision making. ICES Journal of Marine Science. 51(1): $1-13$.

LUTHANS, F. 1977. Organizational behavior (2nd ed.). McGraw-Hill, New York.

MCCOLL, J. C., and R. A. STEVENS. 1997. Australian fisheries management authority: organizational structure and management philosophy. In: Developing and Sustaining World Fisheries Resources: The State of Science and Management. Proceedings of the Second World Fisheries Congress. D. A. Hancock, D. C. Smith, A. Grant and J. P. Beumer (eds.). Brisbane, Australia. CSIRO Publishing, Collingwood, Australia, p. 655-660.

MUNRO, G., and D. GORDON (eds.) 1996. Fisheries and uncertainty: a precautionary approach to resource management. University of Calgary Press, Calgary.

OECD. 1997. Toward sustainable fisheries: economic aspects of the management of living marine resources. Paris, France.

PINKERTON, E. W., and M. WEINSTEIN. 1995. Fisheries that work: sustainability through community-based management. A Report to the David Suzuki Foundation. July, 199 p.

PINKERTON, E. W. 1992. Translating legal rights into management practice: overcoming barriers to the exercise of co-management. Human Organization, winter, 51(4): 330-341.

PINKERTON, E. W. 1993. Co-management efforts as social movements. Alternatives, 19(3): 33-38. 
SEN, S., and. J. R. NIELSEN. 1997. Fisheries co-management: a comparative analysis. In: Developing and Sustaining World Fisheries Resources: The State of Science and Management. Proceedings of the Second World Fisheries Congress. D. A. Hancock, D. C. Smith, A. Grant and J. P. Beumer (eds.) Brisbane, Australia. CSIRO Publishing, Collingwood, Australia, p. 374-382.

STEPHENSON, R. .L., and D. E. LANE. 1995. Fisheries science in fisheries management: a plea for conceptual change. Can. J. Fish. Aquat. Sci., 52(9): 2051-2056.

STEPHENSON, R. L., M. J. POWER, F. J. FIFE, G. D. MELVIN, K. J. CLARK, and S. GAVARIS. MS 1996. Evaluation of the stock status of $4 \mathrm{WX}$ herring. DFO Atl. Fish. Res. Doc., No. 28.

STEPHENSON, R. L., M. J. POWER, J. B. SOCHASKY, F. J. FIFE, G. D. MELVIN, S. GAVARIS, T. D. ILES, and F. PAGE. MS 1995. Evaluation of the stock status of 4WX herring. DFO Atl. Fish. Res. Doc., No. 83.

STEPHENSON, R. L., D. E. LANE, D. ALDOUS, and R. NOWAK. 1993. Management of the 4WX Atlantic herring (Clupea harengus) fishery: an evaluation of recent events. Can. J. Fish. Aquat. Sci., 50: 2742-2757. 
